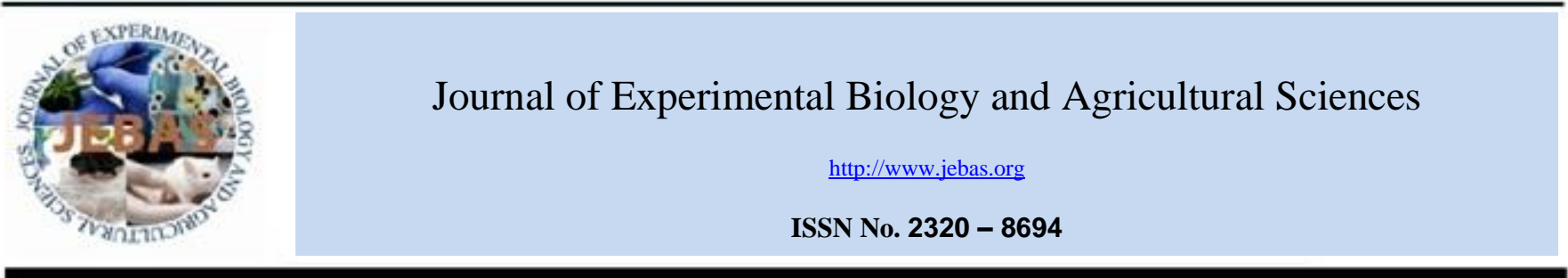

\title{
INFLUENCE OF LIGHT AND HEAVY LANTHANIDES ON THE PHYSIOLOGICAL PROCESSES OF Taraxacum hybernum
}

\section{Vladimir Nikolaevich Vorob'ev ${ }^{1,2}$ (D), Sergei Fedorovich Kotov $^{3}$ (iD), Vera Vladimirovna Nikolenko ${ }^{4}$ (D), Denis Vladimirovich Tishin ${ }^{5}$ (D), Alexander Loenidovich Mikhailov ${ }^{6}$ (iD)}

\author{
${ }^{1}$ Institute of Fundamental Medicine and Biology, Kazan Federal University, Kazan, Russia \\ ${ }^{2}$ Kazan Institute of Biochemistry and Biophysics, FRC Kazan Scientific Center, Russian Academy of Sciences, Kazan, Russia \\ ${ }^{3}$ Faculty of Biology and Chemistry of the Taurida academy of the Crimean federal university named after V.I. Vernadsky, V.I. Vernadsky Crimean Federal \\ University, Simferopol, Russian Federation \\ ${ }^{4}$ Department of Biological Sciences, Faculty of Biology and Chemistry of the Taurida academy of the Crimean federal university named after V.I. Vernadsky, V.I. \\ Vernadsky Crimean Federal University, Simferopol, Russian Federation \\ ${ }^{5}$ Department of Biological Sciences, Institute of Ecology and Nature Management, Kazan Federal University, Kazan, Russia \\ ${ }^{6}$ Department of Biological Sciences, Institute of fundamental medicine and biology, Kazan Federal University, Kazan, Russia
}

Received - September 25, 2020; Revision - November 14, 2020; Accepted - December 13, 2020

Available Online December 15, 2020

DOI: http://dx.doi.org/ 10.18006/2020.8(Spl-2-AABAS).S298.S302

\section{KEYWORDS}

Taraxacum hybernum

NMR-Spectroscopy

Poly (Cis-1,4-Isoprene)

Lanthanides

$\mathrm{CO}_{2}$-Assimilation Intensity

\begin{abstract}
The current study was carried out to study the influence of light and heavy lanthanides on the physiological process of Crimean-Sagyz/ Krim-saghyz (dandelion - Taraxacum hybernum). Lanthanide belongs to the group of light or heavy; infiltration of dandelion (Crimean saghyz) seeds with light and heavy lanthanides solutions increased the germination energy by $26 \%$. The differences in the influence of light (cerium) and heavy (lutetium) were manifested in the quantum efficiency change of the photosystem 2 (PS II). Treatment of leaves with high concentrations $(100 \mu \mathrm{M})$ led to a decrease of $\mathrm{Y}$ (II), moreover, under the influence of light lanthanide, the decrease was greater by $21 \%$. It is assumed that the effect of the used lanthanides on the dandelion photosynthetic apparatus is multidirectional. Cerium influenced the PS II antenna complex, and lutetium influenced the reaction centers. A 10-fold decrease in the concentration did not change the nature of cerium action, except that Y (II) was restored already on the second day after treatment. The effect of lutetium became noticeable only by the 8 th day after treatment when $\mathrm{Y}$ (II) became higher than that of untreated plants. Thus, the results of the study suggested that in dandelion leaves, lanthanides with a concentration of $10 \mu \mathrm{M}$ increased the quantum efficiency of PS II in contrast to cerium.
\end{abstract}

* Corresponding author

E-mail: VNVorobev@kpfu.ru (Vladimir Nikolaevich Vorob’ev)

Peer review under responsibility of Journal of Experimental Biology and Agricultural Sciences.

Production and Hosting by Horizon Publisher India [HPI] (http://www.horizonpublisherindia.in/).

All rights reserved.
All the articles published by Journal of Experimental Biology and Agricultural Sciences are licensed under a Creative Commons Attribution-NonCommercial 4.0 International License Based on a work at www.jebas.org.

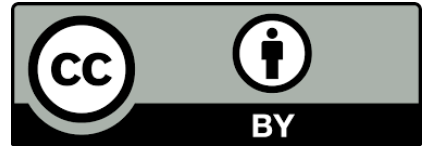




\section{Introduction}

More than a hundred years have been passed since the discovery of the stimulating effect of lanthanides $\left(\mathrm{Ln}^{+3}\right)$, but until now there is no generally accepted understanding of the lanthanide mode of action (Chien \& Ostenhout, 1917; Hu et al., 2004; Migaszewski \& Gałuszka, 2015). According to Goecke et al. (2015) under the magnesium deficiency, the lanthanides lead to the stimulation of growth and rate of photosynthesis in the microalga Desmodesmus quadricauda. Under similar conditions, higher photosynthetic and antioxidant activity was reported in the spinach plants (Chao et al., 2009; Yin et al., 2009; Ze et al., 2009), while chlorophyll biosynthesis, carbon, and nitrogen metabolism were restored in corn (Zhou et al., 2011; Zhao et al., 2012). These effects, obtained at low concentrations of light lanthanides ( $\mathrm{La}, \mathrm{Ce}, \mathrm{Pr}, \mathrm{Nd}$ ), can be explained by the authors from the standpoint of magnesium and calcium replacement by $\mathrm{Ln}^{+3}$ in organometallic compounds with the retention of functions (or even with some activation) of the later. More toxic heavy $\mathrm{Ln}+3$ (Tb, Dy, Ho, Er, Tm, Yb, Lu) are not used in agricultural practice (Gonzalez et al., 2014) because these substances reducing the possibility of obtaining hormesis effects while in the case of light $\mathrm{Ln}+3$ substance application, various physiological processes activate.

The available data on the effect of lanthanides on seed germination of various crops are not unambiguous. Both inhibitory and stimulating effects were found, and this depends on the plant species, lanthanide types, its concentration, and dose (Genty et al., 1996; Hu et al., 2004).

It was assumed that the elements (cerium and lutetium), which are far apart from each other in the lanthanide series, will show differences in their influence on sufficiently studied physiological processes, such as seed germination and the quantum efficiency of the photosystem II (Ramírez-Olvera et al., 2018). The current study aimed to evaluate the effect of light and heavy lanthanides on the physiological process including seed germination of Crimean-Saghyz.

\section{Materials and Methods}

The seeds of the Crimean sagyz dandelion (Taraxacum hybernum Steven) were collected in December 2017 in the vicinity of Sevastopol (Crimean Peninsula). The collected seeds were stored in paper bags at room temperature in a dry place. The seeds of the Crimea-sagyz were germinated in four replicates (50 seeds each) in Petri dishes on settled tap water in the following variants: before stratification; after stratification for 30 days at the temperature of $20{ }^{\circ} \mathrm{C}$; after stratification and infiltration. Infiltration was carried out at the pressure of $10 \mathrm{~Pa}$ for 60 minutes in distilled water and in $100 \mu \mathrm{M}$ solutions of $\mathrm{Ce}\left(\mathrm{NO}_{3}\right)_{3} \times 6 \mathrm{H}_{2} \mathrm{O}$ and $\mathrm{Lu}\left(\mathrm{NO}_{3}\right)_{3} \times 6 \mathrm{H}_{2} \mathrm{O}$. Germination energy was determined on the 4 th day of germination.
The germinated seedlings were planted in 0.5 liter container with "Terra vita" commercial soil. The cultivation of plants was carried out in a climatic chamber at the temperature of $22{ }^{\circ} \mathrm{C}$ with the photoperiod of $16 / 8$ and a luminous flux intensity of $150 \mu \mathrm{mol}$ photons $\mathrm{m}^{-2} \mathrm{~s}^{-1}$ for estimating the effect of lanthanides on the efficiency of photosystem II. After one month of planting, the leaves of each plant were treated with $3 \mathrm{ml}$ solutions of the two selected concentration $(100 \mu \mathrm{M}$ and $10 \mu \mathrm{M})$ of lanthanides.

Variable chlorophyll fluorescence was measured with the help of PAM 2500 fluorometer (Heinz Walz GmbH, Germany) at $22^{\circ} \mathrm{C}$. Fluorescence was recorded in response to the saturation light pulse $\left(\lambda=625 \mathrm{~nm}, 12000 \mu \mathrm{mol}\right.$ of photon $\mathrm{m}^{-2} \mathrm{~s}^{-1}$, the duration made 500 $\mathrm{ms})$. The effective light intensity was $194 \mu \mathrm{mol}$ of photon $\mathrm{m}^{-2} \mathrm{~s}^{-1}$. Effective PSII quantum efficiency (Y (II)), and the quantum yield of light-induced non-photochemical quenching (Y (NPQ)), and the quantum yield of unregulated heat and fluorescence emission (Y (NO)) were measured in light-adapted samples according to the PAM 2500 manual (Heinz Walz GmbH, Germany) and calculated by the equations: $\mathrm{Y}(\mathrm{II})=\left(F^{\prime}{ }_{m}-F_{s}\right) / F^{\prime}{ }_{m} ; \mathrm{Y}(\mathrm{NPQ})=F_{s} / F^{\prime}{ }_{m}-F / F_{m}$; $\mathrm{Y}(\mathrm{NO})=F_{s} / F_{m}$, where $F_{s}$ - the stationary level, and $F^{\prime}{ }_{m}$ - the lightinduced maximum level of chlorophyll fluorescence in lightadapted leaves (Wang et al., 2014).

All experiments were performed in six biological agilities. The results were statistically analyzed using the OriginPro 9.0 software. The statistical significance of differences between the variants was assessed by the Mann-Whitney U test at $\mathrm{p}<0.05$.

\section{Results and Discussion}

The available data on the effect of lanthanides on seed germination of various crops are not unambiguous. Previous studies suggested both inhibitory and stimulating and it depends on the plant species, types of lanthanide, and its concentration (Genty et al., 1996; Hu et al., 2004). Despite the differences in the toxicity of light and heavy lanthanides (Gonzalez et al., 2014), one-hour infiltration of Crimea-sagyz seeds with $100 \mu \mathrm{M}$ solutions of $\mathrm{Ce}\left(\mathrm{NO}_{3}\right)_{3}$ and $\mathrm{Lu}$ $\left(\mathrm{NO}_{3}\right)_{3}$ increased the germination energy (Table 1). Infiltration of stratified seeds in water did not affect the germination energy, in contrast to the infiltration in solutions of cerium and lutetium nitrates, which led to the germination energy increase by $26 \%$.

Table 1 The seed germination energy of the Crimean-sagyz dandelion (in\%) after stratification and infiltration with $100 \mu \mathrm{M} \mathrm{Ce}\left(\mathrm{NO}_{3}\right)_{3}$ and $\mathrm{Lu}\left(\mathrm{NO}_{3}\right)_{3}$ at a pressure of $10 \mathrm{~Pa}$ for 60 minutes

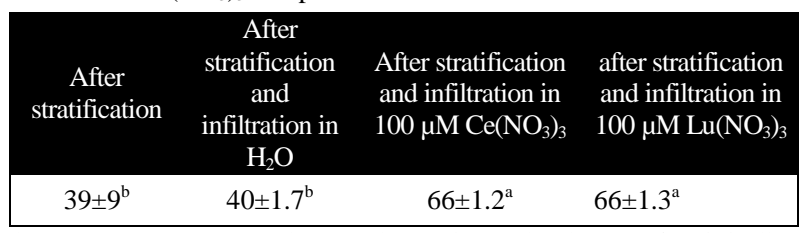

Shown mean $\pm S D, n=6$. The same letters denote the absence of statistically significant differences between the Mann Whitney U tests at $\mathrm{p}<0.05$ 
Differences between cerium and lutetium germination energy are nonsignificant and this might be because of the less incubation time which is not sufficient for the inhibitory effect or both lanthanides can replace calcium in bioorganic compounds and thereby trigger biochemical reactions responsible for the exit of seeds from dormancy.

The differences in the effect of lanthanum and cerium have manifested the efficiency of photosystem II when dandelion leaves were treated with these salts solutions. It is known that when leaves were treated with lanthanide ions solutions, lanthanoid enters into the cell by endocytosis processes (Hendrickson et al., 2004). Lanthanum and cerium penetrated in the cell did not have a similar effect on Y(II). Figure 1 shows the slow kinetics of the photochemical conversion quantum yield of absorbed light energy Y (II). The greatest decrease in Y (II) by $21 \%$ was caused by cerium 24 hours after the treatment of the Crimea-sagyz dandelion leaves while this inhibition was $8.6 \%$ in Lutetium treatment.

The decrease in the effective quantum yield of chlorophyll Y (II) fluorescence under the influence of $100 \mu \mathrm{M} \mathrm{Ce}\left(\mathrm{NO}_{3}\right)_{3}$ was due to the increase of the quantum yield fraction of the energy part controlled dissipation Y(NPQ) (Figure 2), which corresponds to the fraction of energy dissipated in the form of heat by adjustable photoprotective mechanism (Ikeuchi et al., 2014). Nonphotochemical quenching also includes $\mathrm{Y}(\mathrm{NO})$, a constitutive energy loss that is passively dissipated in the form of heat and fluorescence, mainly due to closed PS II reaction centers (Samson et al., 2019). Under the influence of $100 \mu \mathrm{M} \mathrm{Lu}\left(\mathrm{NO}_{3}\right)_{3}$, the increase of $\mathrm{Y}(\mathrm{NO})$ causes a decrease in the $\mathrm{Y}(\mathrm{II})$ (Figure 3).

A 10-fold decrease in concentration did not change the nature of cerium action, except that Y (II) was restored on the second day after treatment (Figure 1b). The effect of lutetium became noticeable only on the 8th day after treatment when Y (II) became higher than in untreated plants (Figure 4).

\section{Conclusions}

Lanthanide belongs to the light or heavy group, infiltration of the Crimean sagyz dandelion seeds in the lanthanide solutions increased the germination energy. Differences in the influence of light (cerium) and heavy (lutetium) were manifested in the quantum efficiency which changes the photosystem 2 (PS II). Treatment of leaves with high concentrations $(100 \mu \mathrm{M})$ led to a decrease in $\mathrm{Y}$ (II), moreover, under the influence of light lanthanide, it shows higher reduction. Further, results of the study suggested that cerium influenced the PS II antenna complex while lutetium influenced its reaction centers. A 10-fold decrease in concentration did not change the nature of cerium action, except that $\mathrm{Y}$ (II) was restored on the second day after treatment. The

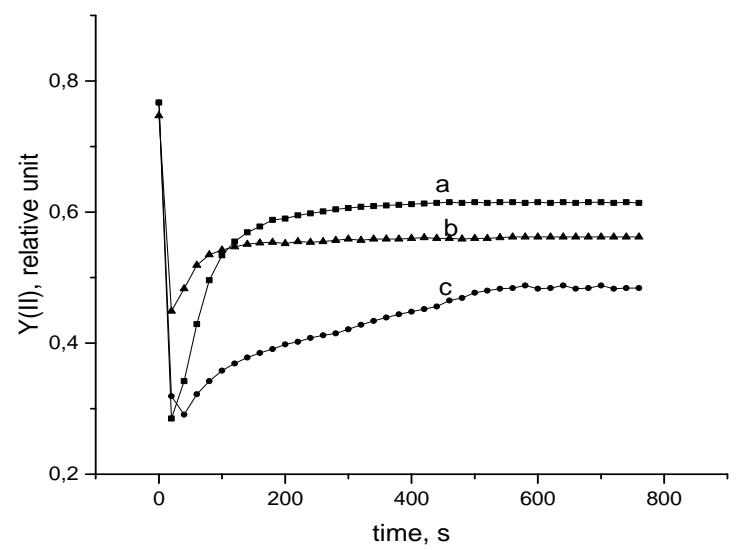

Figure 1 Slow kinetics of the quantum yield of the photochemical conversion of absorbed light energy 24 hours after leaf treatment with salt solutions $\left(\mathrm{a}-\mathrm{H}_{2} \mathrm{O}, \mathrm{b}-100 \mu \mathrm{M} \mathrm{Lu}\left(\mathrm{NO}_{3}\right) 3, \mathrm{c}-100 \mu \mathrm{M} \mathrm{Ce}\left(\mathrm{NO}_{3}\right)\right.$ 3)

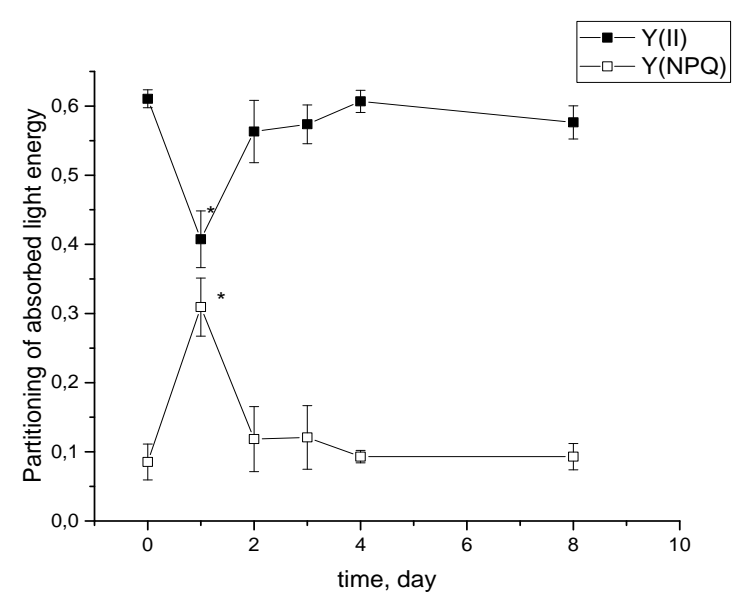

Figure 2 Separation of absorbed light energy under the influence of $100 \mu \mathrm{M} \mathrm{Ce}$ (NO3) 3); * - a statistically significant difference from the zero point is indicated at $\mathrm{p}=0.05$.

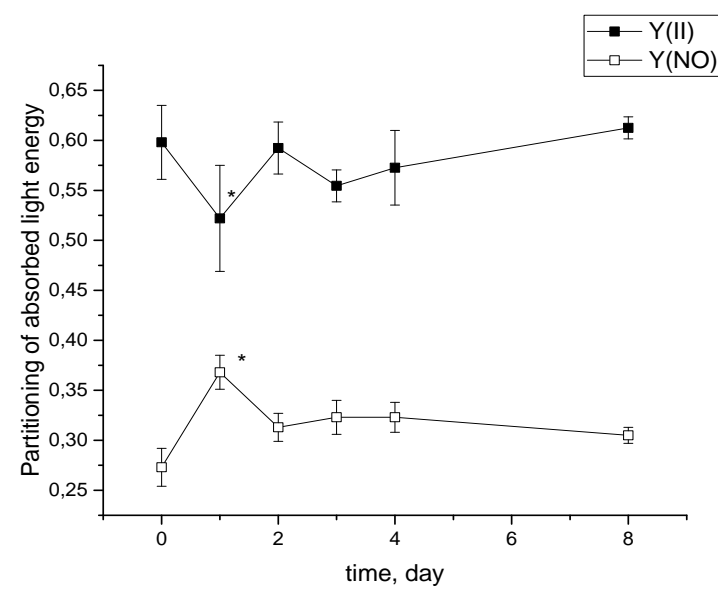

Figure 3 Separation of absorbed light energy under the influence of $100 \mu \mathrm{M} \mathrm{Lu}(\mathrm{NO} 3) 3$ ); * - a statistically significant difference from the zero point at $\mathrm{p}=0.05$ is indicated. 


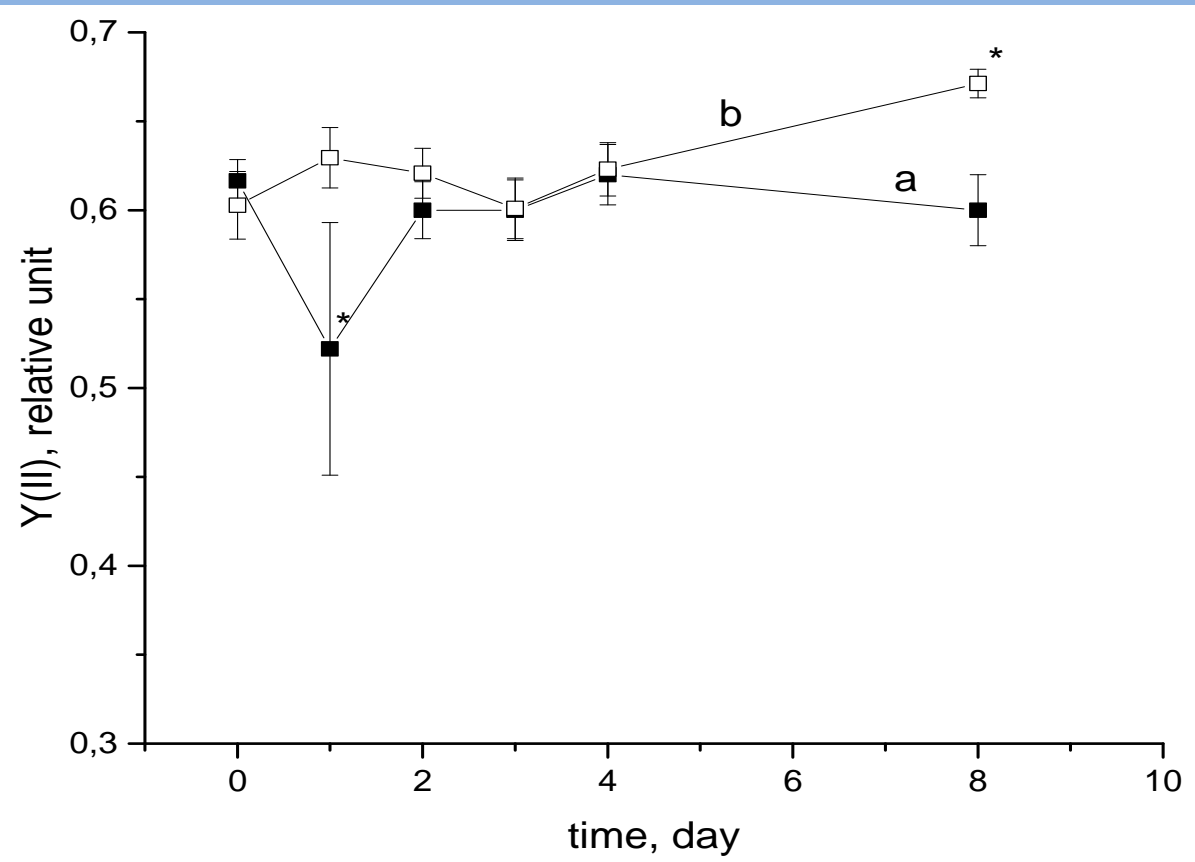

Figure 4 Dynamics of the quantum efficiency of photosystem 2 under the influence of $10 \mu \mathrm{M}$ solutions: a - Ce (NO3) 3; b - Lu (NO3) 3); * - a statistically significant difference from the zero point at $\mathrm{p}=0.05$ is indicated.

effect of lutetium became noticeable only on the 8th day after treatment when Y (II) became higher than that of untreated plants. From the results of the study, it can be concluded that lanthanide treatment increased the quantum efficiency of PS II in dandelion leaves of Krym-sagyz and it was higher than the cerium treatment at the concentration of $10 \mu \mathrm{M}$.

\section{Acknowledgements}

The work is performed according to the Russian Government Program of Competitive Growth of Kazan Federal University.

\section{Conflict Of Interest}

Authors would hereby like to declare that there is no conflict of interests that could possibly arise.

\section{References}

Chao L, Weiqian C, Yun L, Hao H, Liang C, Xiaoqing L, Fashui H (2009) Cerium under calcium deficiency-influence on the antioxidative defense system in spinach plants. Plant and Soil 323(1-2):285-94.

Chien SQ, Ostenhout WJ (1917) Physiological function of Ba, Sr, and Ce on water-floss (Spirogyra). Baranical Gazette 63:406-9.

Genty B, Harbinson J, Cailly AL, Rizza F (1996) Fate of excitation at PS II in leaves: the non-photochemical side. Inthird BBSRC Robert Hill symposium on photosynthesis 31 .
Goecke F, Jerez CG, Zachleder V, Figueroa FL, Bišová K, Řezanka T, Vítová M (2015) Use of lanthanides to alleviate the effects of metal ion-deficiency in Desmodesmus quadricauda (Sphaeropleales, Chlorophyta). Frontiers in microbiology 6:2.

Gonzalez V, Vignati DA, Leyval C, Giamberini L (2014) Environmental fate and ecotoxicity of lanthanides: are they a uniform group beyond chemistry? Environment international $71: 148-57$.

Ramírez-Olvera SM, Trejo-Téllez LI, García-Morales S, PérezSato JA, Gómez-Merino FC (2018) Cerium enhances germination and shoot growth, and alters mineral nutrient concentration in rice. PLoS One13(3):e0194691.

Hendrickson L, Furbank RT, Chow WS (2004) A simple alternative approach to assessing the fate of absorbed light energy using chlorophyll fluorescence. Photosynthesis Research 82(1):73.

Hu Z, Richter H, Sparovek G, Schnug E (2004) Physiological and biochemical effects of rare earth elements on plants and their agricultural significance: a review. Journal of Plant Nutrition 27(1):183-220.

Ikeuchi M, Uebayashi N, Sato F, Endo T (2014) Physiological functions of PsbS-dependent and PsbS-independent NPQ under naturally fluctuating light conditions. Plant and Cell Physiology 55(7):1286-95. 
Migaszewski ZM, Gałuszka A (2015) The characteristics, occurrence, and geochemical behavior of rare earth elements in the environment: a review. Critical Reviews in Environmental Science and Technology 45(5):429-71.

Samson G, Bonin L, Maire V (2019) Dynamics of regulated YNPQ and non-regulated YNO energy dissipation in sunflower leaves exposed to sinusoidal lights. Photosynthesis research 141(3):315-30.

Wang L, Li J, Zhou Q, Yang G, Ding XL, Li X, Cai CX, Zhang Z, Wei HY, Lu TH, Deng XW (2014) Rare earth elements activate endocytosis in plant cells. Proceedings of the National Academy of Sciences 111(35):12936-41.

Yin S, Ze Y, Liu C, Li N, Zhou M, Duan Y, Hong F (2009) Cerium relieves the inhibition of nitrogen metabolism of spinach caused by magnesium deficiency. Biological Trace Element Research 132(1-3):247-58.

Ze Y, Yin S, Ji Z, Luo L, Liu C, Hong F (2009) Influences of magnesium deficiency and cerium on antioxidant system of spinach chloroplasts. Biometals 22(6):941.

Zhao H, Zhou Q, Zhou M, Li C, Gong X, Liu C, Qu C, Wang L, Si W, Hong F (2012) Magnesium deficiency results in damage of nitrogen and carbon cross-talk of maize and improvement by cerium addition. Biological Trace Element Research 148(1):102-9.

Zhou M, Gong X, Ying W, Chao L, Hong M, Wang L, Fashui H (2011) Cerium relieves the inhibition of chlorophyll biosynthesis of maize caused by magnesium deficiency. Biological Trace Element Research 143(1):468-77. 